\title{
Effect of Diameter on Bond Failure of Steel Rebar Embedded into Concrete Using Epoxies at High Temperatures
}

\author{
Thanyawat Pothisiri ${ }^{\mathrm{a}}$, Pitcha Jongvivatsakul ${ }^{\mathrm{b},}$, Phuwisorn Horsangchai $^{\mathrm{c}}$, \\ and Prakit Phornwiriyatham ${ }^{\mathrm{d}}$ \\ Department of Civil Engineering, Faculty of Engineering, Chulalongkorn University, Bangkok 10330, \\ Thailand \\ E-mail: athanyawat.p@chula.ac.th, bpitcha.j@chula.ac.th (Corresponding author), \\ cjackpotcode222@gmail.com, dprakit_irre64@hotmail.com
}

\begin{abstract}
A series of pull-out tests were conducted to examine the bond deterioration of epoxy resins at elevated temperatures through the relationship between the critical temperature and bond stress. The steel rebars investigated were deformed bars with varying diameters of $12 \mathrm{~mm}, 16 \mathrm{~mm}, 20 \mathrm{~mm}$ and $25 \mathrm{~mm}$. Two different types of epoxy resins were used. The test results show that the critical temperature for both types of epoxy resins tends to decrease with the increasing bond stress. In addition, the critical temperature is significantly lower for steel rebar with larger diameters. Meanwhile, the effect from varying types of epoxy resins on the bond characteristics is negligible. In order to illustrate the effect of rebar size, a mechanical model for the adhesive bonding stress between steel rebar and concrete interface at elevated temperatures is presented. The model provides good prediction of the bond stress at failure temperature.
\end{abstract}

Keywords: Concrete, steel rebar, elevated temperatures, bond failure, epoxy resin, pull-out.

ENGINEERING JOURNAL Volume 22 Issue 3

Received 3 October 2017

Accepted 14 March 2018

Published 28 June 2018

Online at http://www.engj.org/

DOI:10.4186/ej.2018.22.3.93 


\section{Introduction}

Epoxy resins have increasingly been used as bonding materials for structural elements in modern construction [1-3]. Among many applications, epoxy resins are used to bond steel rebars into existing cast-in-place or precast concrete structures. Previous studies have shown the advantage of concrete/steel bonds using epoxy resins in terms of higher bond strength compared with mechanical steel-to-concrete anchors $[4,5]$. The bond strength at normal temperature is affected by many parameters such as concrete strength $[6,7]$, epoxy type [8], embedded length [9] and environmental condition [10]. At elevated temperatures, however, a significant decrease of the bond capacity has been reported due to a decrease of the resin's modulus with an increase of temperature during the glass transition period [11-13]. The decrease in the load bearing capacity of the bond can lead to collapse of the structural systems after exposure to high temperatures.

To date, limited experimental data is available on the degradation of bond strength of epoxy resins between concrete and steel rebar at elevated temperatures. Most studies have investigated residual bond strength after exposing the specimen to high temperatures and cooling it back to laboratory temperature before performing a pull-out test [14-17]. Tests with both thermal loading and pull-out being performed simultaneously have been conducted only for specimens with a $12 \mathrm{~mm}$ diameter rebar [11] and consequently the influence of rebar size on bond failure of epoxy resins has not been clarified. Due to variation of actual rebar's diameter used in construction, the effect of rebar size on bond failure of epoxy resins at high temperatures must be studied.

This paper is aimed to examine the effect of rebar size on the results of pull-out tests performed at elevated temperatures on specimens containing different sizes of steel rebar anchored in concrete cylinders with epoxy resins. A series of tests were carried out using an electric oven on pull-out specimens with varying rebar diameters between $12 \mathrm{~mm}$ to $25 \mathrm{~mm}$. A mechanical model is also proposed to examine the effect of rebar size on bond failure of steel reinforcement into concrete using epoxy resin at elevated temperatures.

\section{Materials and Methods}

\subsection{Specimen}

Figure 1 illustrates the pull-out specimen used for the current study, which consisted of a concrete cylinder (150 mm diameter, $300 \mathrm{~mm}$ height) bordered by a $2.8 \mathrm{~mm}$ thick steel layer to avoid cracks on the exterior lateral side of the cylinder. A deformed steel rebar was anchored in the concrete cylinder with the embedment depth of ten times the rebar diameter in order to simulate actual construction practice. The rebar diameter was specified as $12 \mathrm{~mm}, 16 \mathrm{~mm}, 20 \mathrm{~mm}$ and $25 \mathrm{~mm}$. The steel rebars with these four different diameters are referred to herein as DB12, DB16, DB20 and DB25, respectively.

For each pull-out specimen, the anchor hole was drilled in the hardened concrete, with a diameter of 4 $\mathrm{mm}$ larger than the steel rebar, a few days before the pull-out test. The epoxy resin was injected for bonding the rebar after the hole was cleaned according to the resin supplier's specifications. Two type-k thermocouples were installed on the steel rebar at $10 \mathrm{~mm}$ from the concrete surface (TS1) and at the deepest embedded part (TS2) as illustrated in Fig. 2 in order to monitor the temperatures of the epoxy resin throughout the test.

Ready-mix concrete with the characteristic compressive strength of $28 \mathrm{MPa}$ was used to cast the concrete cylinders in a single batch. Tables 1-3 present the properties of Portland cement (ASTM Type I), aggregates, and the mixture proportions given by the manufacturer of concrete, respectively. The maximum size of coarse aggregate is $19 \mathrm{~mm}$. The concrete specimens had a compressive strength that ranged between 27.8 and 30.6 MPa. The strength was determined by averaging five compressive tests performed on the $150 \times 300 \mathrm{~mm}$ cylinders after curing for 28 days at ambient temperature and moisture [18]. The properties of the steel rebar are listed in Table 4 . The yield strength, tensile strength and elongation of steel rebars with different diameters were different due to variation in their manufacturing process. However, all tested rebars passed the quality grade for SD40 according to TIS-24-2548 [19], which specifies that the yield strength shall not be less than $390 \mathrm{MPa}$. Moreover, this observed variation in strength does not affect the discussion for the current study because all specimens exhibited bond deterioration of epoxy resins at failure without yielding of steel rebars. The general information given by the manufacturers on the epoxy resins are shown in Table 5. Note that two types of epoxy resins, E1 and E2, from different manufacturers were used to examine the effect of rebar size. 


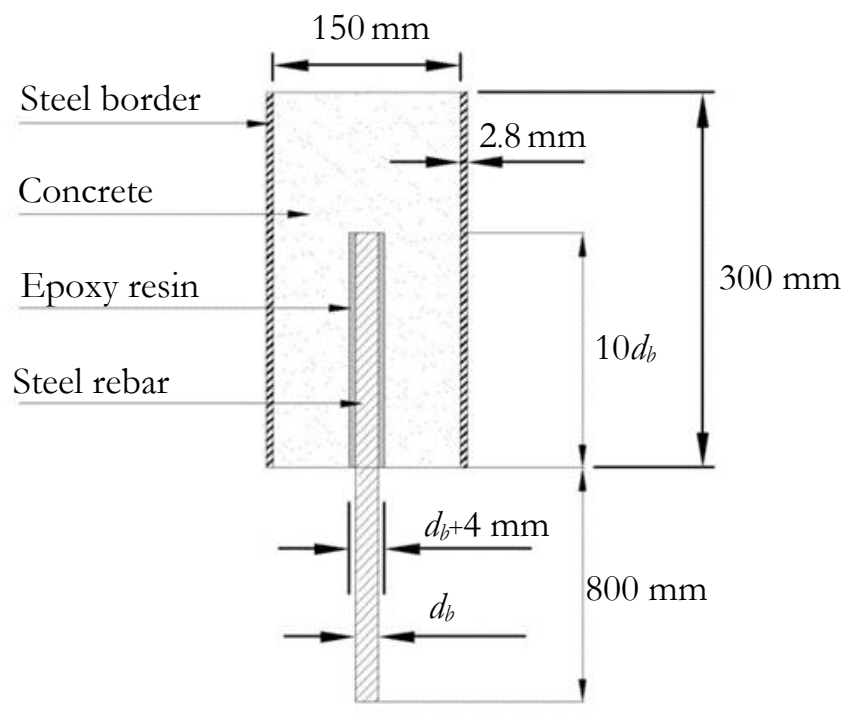

Fig. 1. Pull-out specimen.

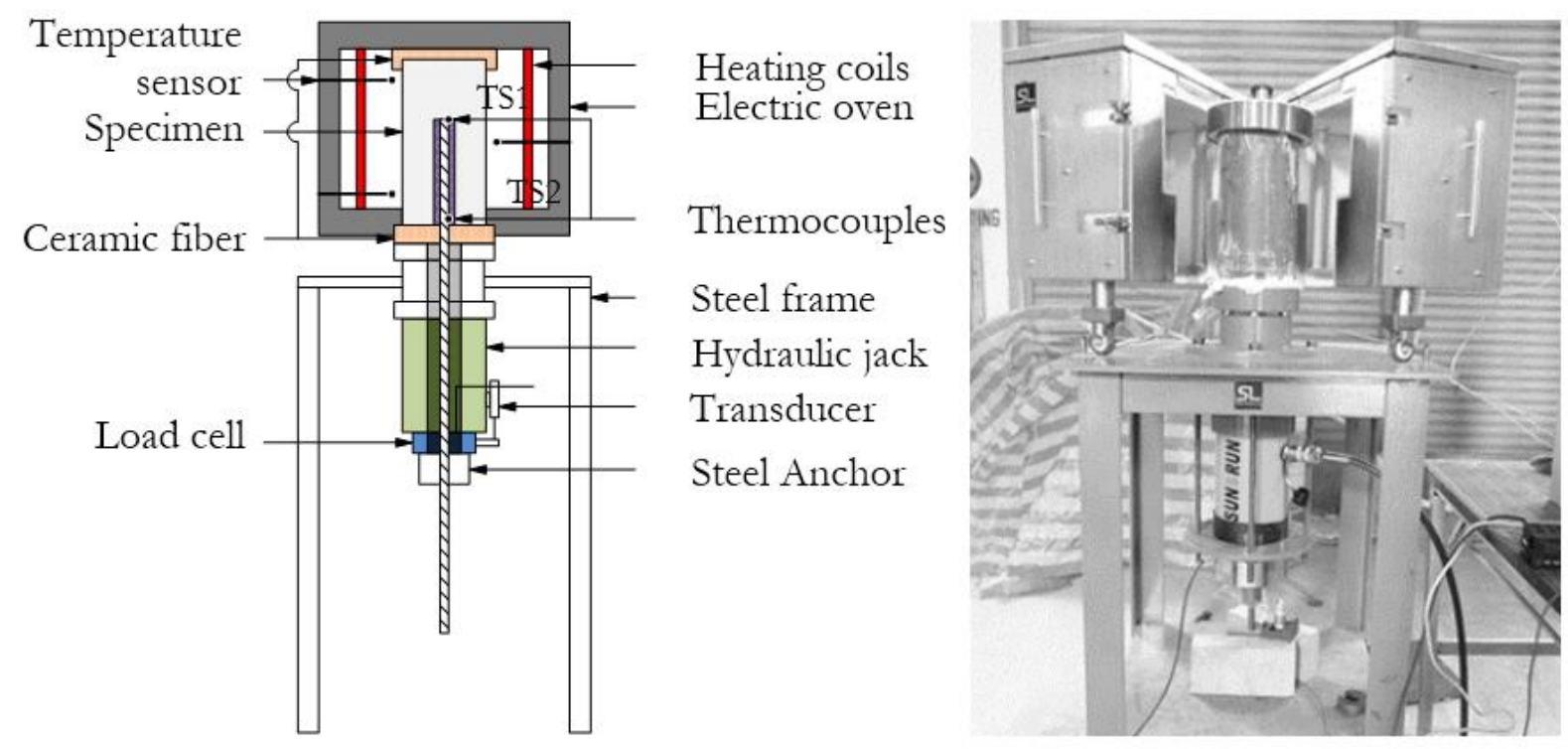

Fig. 2. Electric heating device.

Table 1. Physical and mechanical properties of Portland cement.

\begin{tabular}{lc}
\hline Properties & Values \\
\hline Specific gravity & 3.15 \\
Initial setting time & 106 minutes \\
Final setting time & 173 minutes \\
Fineness : Air permeability test & $3530 \mathrm{~cm}^{2} / \mathrm{g}$ \\
Soundness : Autoclave expansion & $0.0 \%$ \\
Air content of mortar & $7.2 \%$ \\
\hline
\end{tabular}


Table 2. Properties of aggregates.

\begin{tabular}{lcc}
\hline Type & Fine aggregate & Coarse aggregate \\
\hline Specific gravity & 2.65 & 2.70 \\
Fineness modulus & 2.34 & 6.53 \\
Passing $4.75 \mathrm{~mm}$ sieve & $100 \%$ & $5 \%$ \\
Specific surface area $\left(\mathrm{cm}^{2} / \mathrm{kg}\right)$ & 31913 & 2671 \\
Average diameter $(\mathrm{mm})$ & 0.78 & 11.65 \\
\hline
\end{tabular}

Table 3. Mix proportion of concrete.

\begin{tabular}{|c|c|c|c|c|c|c|}
\hline $\begin{array}{c}\text { Water to } \\
\text { binder } \\
\text { ratio }\end{array}$ & $\begin{array}{l}\text { Water } \\
\left(\mathrm{kg} / \mathrm{m}^{3}\right) \\
\end{array}$ & $\begin{array}{c}\text { Cementitious } \\
\text { materials } \\
\left(\mathrm{kg} / \mathrm{m}^{3}\right) \\
\end{array}$ & $\begin{array}{c}\text { Fine } \\
\text { aggregate } \\
\left(\mathrm{kg} / \mathrm{m}^{3}\right)\end{array}$ & $\begin{array}{c}\text { Coarse } \\
\text { aggregate } \\
\left(\mathrm{kg} / \mathrm{m}^{3}\right)\end{array}$ & $\begin{array}{l}\text { Admixture } \\
\left(\mathrm{cc} / \mathrm{m}^{3}\right)\end{array}$ & $\begin{array}{l}\text { Slump } \\
(\mathrm{cm})\end{array}$ \\
\hline 0.57 & 195 & 342 & 770 & 1,150 & 1370 & $7.5-12.5$ \\
\hline
\end{tabular}

Table 4. Properties of steel reinforcement bars.

\begin{tabular}{cccc}
\hline $\begin{array}{c}\text { Diameter of steel } \\
\text { reinforcement }(\mathbf{m m})\end{array}$ & $\begin{array}{c}\text { Yield strength } \\
\mathbf{( M P a}\end{array}$ & $\begin{array}{c}\text { Tensile strength } \\
\mathbf{( M P a})\end{array}$ & $\begin{array}{c}\text { Elongation } \\
\mathbf{( \% )}\end{array}$ \\
\hline 12 & 496 & 606 & 25.0 \\
16 & 506 & 637 & 22.5 \\
20 & 479 & 610 & 26.0 \\
25 & 519 & 646 & 25.3 \\
\hline
\end{tabular}

Table 5. Properties of epoxy resins.

\begin{tabular}{lcc}
\hline Epoxy resin & E1 & E2 \\
\hline Bond strength* & $17 \mathrm{MPa}$ & $14 \mathrm{MPa}$ \\
Gel time & $20 \mathrm{mins}$ & $30 \mathrm{mins}$ \\
Initial curing time & $8 \mathrm{~h}$ & $6 \mathrm{~h}$ \\
Final curing time & $24 \mathrm{~h}$ & $12 \mathrm{~h}$ \\
\hline
\end{tabular}

*At $25^{\circ} \mathrm{C}$ for DB12 rebar with $120 \mathrm{~mm}$ embedment depth.

\subsection{Pull-out Test}

The pull-out tests were performed by applying a specified tensile load to the steel rebar with the concrete cylinder enclosed in an electric oven (Fig. 2). The tests were conducted similar to the previous work reported in the literature [11]. The electric oven is equipped with 2 heating coils located on opposite sides of the specimen and 3 temperature sensors installed next to the heating coils at the top, middle and bottom of the oven as illustrated in Fig. 2. The specimen was placed at the center of the oven. Ceramic fiber was used as the thermal insulant in this test. A load cell and a displacement transducer were installed as shown in Fig. 2 in order to measure the applied load and slippage of rebar. The tensile load was applied before heating and was kept constant by a hollow jack throughout the test. The specimen was then progressively heated at a rate of $10^{\circ} \mathrm{C} / \mathrm{min}$ up to $500^{\circ} \mathrm{C}$ after which the target temperature was maintained until failure of the bond. The bond failure was identified through a sharp drop of the tensile load or instant slippage of the rebar with the maximum slippage set at $10 \mathrm{~mm}$, at which point the mean value of the temperatures measured by TS1 and TS2 (Fig. 2) was taken as the failure temperature.

Based on the previous studies reported by Pinoteau et al. [11] and Cook et al. [20], a uniform bond stress distribution along the embedded length of the steel rebar is assumed and can be written as

$$
\tau_{b}=F / \pi d_{b} l_{b}
$$


in which $\tau_{b}$ is the bond stress, $F$ is the applied tensile load, $d_{b}$ is the diameter of the steel rebar and $l_{b}$ is the embedded length of the steel rebar.

The epoxy resin's bond is characterized by the failure temperature vs. bond stress curve obtained by performing pull-out tests at different loads. For each rebar diameter, two pull-out tests were performed with different tensile loads to generate varying bond stresses in the range of 0.2 to $7 \mathrm{MPa}$. Note that each epoxy resin's bond at room temperature is higher than $7 \mathrm{MPa}$. Table 6 summarizes the levels of loads used to evaluate bond failure temperatures for specimens with different rebar diameters. Two repeatability tests have been performed for each rebar diameter to cautiously avoid uncertainty on the test results except for DB12 and DB25 using E2 epoxy resin due to limited availability of the material supply.

\subsection{Instrumentation}

The electric oven is equipped with three temperature sensors located next to the heating coils (Fig. 2). The oven temperature was regulated automatically through the acquisition of temperature data performed at $3 \mathrm{~s}$ intervals. The hydraulic jack was controlled manually to maintain the tensile load. A displacement transducer was installed on the jack to monitor slippage of the steel rebar. The epoxy resin temperatures measured by TS1 and TS2, and jack displacements were recorded through the Kyowa EDX-100A4H data acquisition system. A higher acquisition frequency of $1 \mathrm{~s}$ was set for the epoxy resin temperatures and jack displacements in order to identify the precise pull-out failure time.

\section{Results and Discussions}

The pull-out test results are reported herein with an exception of the specimens tested at the initial room temperature $\left(25^{\circ} \mathrm{C}\right)$ in which failure was due to rebar rupture under the applied load. The average value of failure temperatures for each experimental case is summarized in Table 6.

\subsection{Failure Mode}

As observed for each specimen after the pull-out test shown in Tables 7-8, bond failure occurred at either the steel bar/resin interface or resin/concrete interface along the embedded length of the rebar without cracking in the concrete. This so-called shearing-off failure has been identified for all of the tested specimens. The results are in line with the experimental data reported in the literature [11] in which shearing-off failure has been identified as the dominant mode of bond failure for polymer adhesives anchoring steel bars into concrete at high temperatures.

\subsection{Failure Temperature vs. Bond Stress Curve}

The bond strength deterioration of an epoxy resin under elevated temperatures can be characterized by its failure temperature vs. bond stress, which is computed by Eq. (1), diagram obtained through pull-out tests performed at different loads [11]. Figure 3 presents the E1 epoxy resin curves for four different rebar diameters. In order to assess the differences between results, a curve-fitting technique was employed using both power trend and logarithmic functions. A set of logarithmic functions have been identified to yield the best-fit curves as also illustrated in Fig. 3. For a given rebar diameter, the bond failure temperature decreases with increasing stress. Furthermore, for a given bond stress, the failure temperature is lower for steel rebar with larger diameters. The effect of rebar size is more pronounced when the results are compared between DB12 and DB25 rebars. Table 9 summarizes the equations between critical bond stress, $\tau_{e}^{c r}$ (MPa) and failure temperature, $T_{e}\left({ }^{\circ} \mathrm{C}\right)$ for each rebar diameter and epoxy type that yield the best-fit to each series of data point, the corresponding coefficients of determination $\left(\mathrm{R}^{2}\right)$ and the standard errors of estimates. It should be noted that the derived equations are valid for the experimental conditions of this study and are not generalized expressions. 
Table 6. Experimental cases and results.

\begin{tabular}{|c|c|c|c|c|c|c|}
\hline \multirow{2}{*}{$\begin{array}{c}\text { Epoxy } \\
\text { resins } \\
\text { types }\end{array}$} & \multirow[b]{2}{*}{$\begin{array}{c}d_{b} \\
(\mathrm{~mm})\end{array}$} & \multirow[b]{2}{*}{$\begin{array}{l}\text { Bond stress, } \tau_{b} \\
(\mathrm{MPa})\end{array}$} & \multirow[b]{2}{*}{$\begin{array}{c}\text { Applied tensile loads, } \\
\qquad F(\mathrm{kN})\end{array}$} & \multicolumn{3}{|c|}{ Failure temperature $\left({ }^{\circ} \mathrm{C}\right)$} \\
\hline & & & & $\begin{array}{l}\text { Specimen } \\
\text { No. } 1\end{array}$ & $\begin{array}{l}\text { Specimen } \\
\text { No. } 2\end{array}$ & $\begin{array}{c}\text { Average } \\
\text { value }\end{array}$ \\
\hline \multirow{24}{*}{ E1 } & \multirow{6}{*}{12} & 7 & 31.7 & 84.3 & 65.7 & 75.0 \\
\hline & & 3.5 & 15.8 & 89.2 & 96.8 & 93.0 \\
\hline & & 1.75 & 7.9 & 259.8 & 256.9 & 258.4 \\
\hline & & 0.875 & 4 & 279.7 & 279.0 & 279.4 \\
\hline & & 0.4375 & 2 & 293.3 & 301.4 & 297.4 \\
\hline & & 0.21875 & 1 & 302.9 & 316.3 & 309.6 \\
\hline & \multirow{6}{*}{16} & 7 & 56.3 & 93.9 & 82.2 & 88.0 \\
\hline & & 3.5 & 28.1 & 86.0 & 98.2 & 92.1 \\
\hline & & 1.75 & 14.1 & 247.6 & 217.0 & 232.3 \\
\hline & & 0.875 & 7 & 278.7 & 264.7 & 271.7 \\
\hline & & 0.4375 & 3.5 & 305.5 & 308.4 & 306.9 \\
\hline & & 0.21875 & 1.8 & 311.0 & 318.4 & 314.7 \\
\hline & \multirow{6}{*}{20} & 7 & 88 & 64.3 & 62.0 & 63.1 \\
\hline & & 3.5 & 44 & 66.2 & 65.4 & 65.8 \\
\hline & & 1.75 & 22 & 156.5 & 171.7 & 164.1 \\
\hline & & 0.875 & 11 & 276.7 & 280.9 & 278.8 \\
\hline & & 0.4375 & 5.5 & 296.6 & 298.0 & 297.3 \\
\hline & & 0.21875 & 2.7 & 277.0 & 305.8 & 291.4 \\
\hline & \multirow{6}{*}{25} & 7 & 137.4 & 57.6 & 58.7 & 58.1 \\
\hline & & 3.5 & 68.7 & 76.5 & 62.7 & 69.6 \\
\hline & & 1.75 & 34.4 & 111.2 & 119.2 & 115.2 \\
\hline & & 0.875 & 17.2 & 254.2 & 264.7 & 259.4 \\
\hline & & 0.4375 & 8.6 & 303.7 & 305.5 & 304.6 \\
\hline & & 0.21875 & 4.3 & 308.9 & 326.1 & 317.5 \\
\hline \multirow{24}{*}{ E2 } & \multirow{6}{*}{12} & 7 & 31.7 & 61.4 & - & 61.4 \\
\hline & & 3.5 & 15.8 & 85.2 & - & 85.2 \\
\hline & & 1.75 & 7.9 & 127.4 & - & 127.4 \\
\hline & & 0.875 & 4 & 262.0 & - & 262.0 \\
\hline & & 0.4375 & 2 & 273.6 & - & 273.6 \\
\hline & & 0.21875 & 1 & 296.7 & - & 296.7 \\
\hline & \multirow{6}{*}{16} & 7 & 56.3 & 69.1 & 85.8 & 77.5 \\
\hline & & 3.5 & 28.1 & 94.9 & 120.9 & 107.9 \\
\hline & & 1.75 & 14.1 & 116.6 & 130.3 & 123.5 \\
\hline & & 0.875 & 7 & 243.2 & 107.2 & 175.2 \\
\hline & & 0.4375 & 3.5 & 286.2 & 290.2 & 288.2 \\
\hline & & 0.21875 & 1.8 & 311.1 & 315.3 & 313.2 \\
\hline & \multirow{6}{*}{20} & 7 & 88 & 52.9 & 57.2 & 55.1 \\
\hline & & 3.5 & 44 & 85.2 & 90.5 & 87.9 \\
\hline & & 1.75 & 22 & 105.1 & 119.0 & 112.0 \\
\hline & & 0.875 & 11 & 255.2 & 252.0 & 253.6 \\
\hline & & 0.4375 & 5.5 & 274.7 & 271.3 & 273.0 \\
\hline & & 0.21875 & 2.7 & 299.6 & 288.4 & 294.0 \\
\hline & \multirow{6}{*}{25} & 7 & 137.4 & 65.5 & - & 65.5 \\
\hline & & 3.5 & 68.7 & 79.9 & - & 79.9 \\
\hline & & 1.75 & 34.4 & 93.6 & - & 93.6 \\
\hline & & 0.875 & 17.2 & 243.8 & - & 243.8 \\
\hline & & 0.4375 & 8.6 & 279.0 & - & 279.0 \\
\hline & & 0.21875 & 4.3 & 288.5 & - & 288.5 \\
\hline
\end{tabular}


Table 7. Failure mode of the pull-out specimens using E1 epoxy resin.

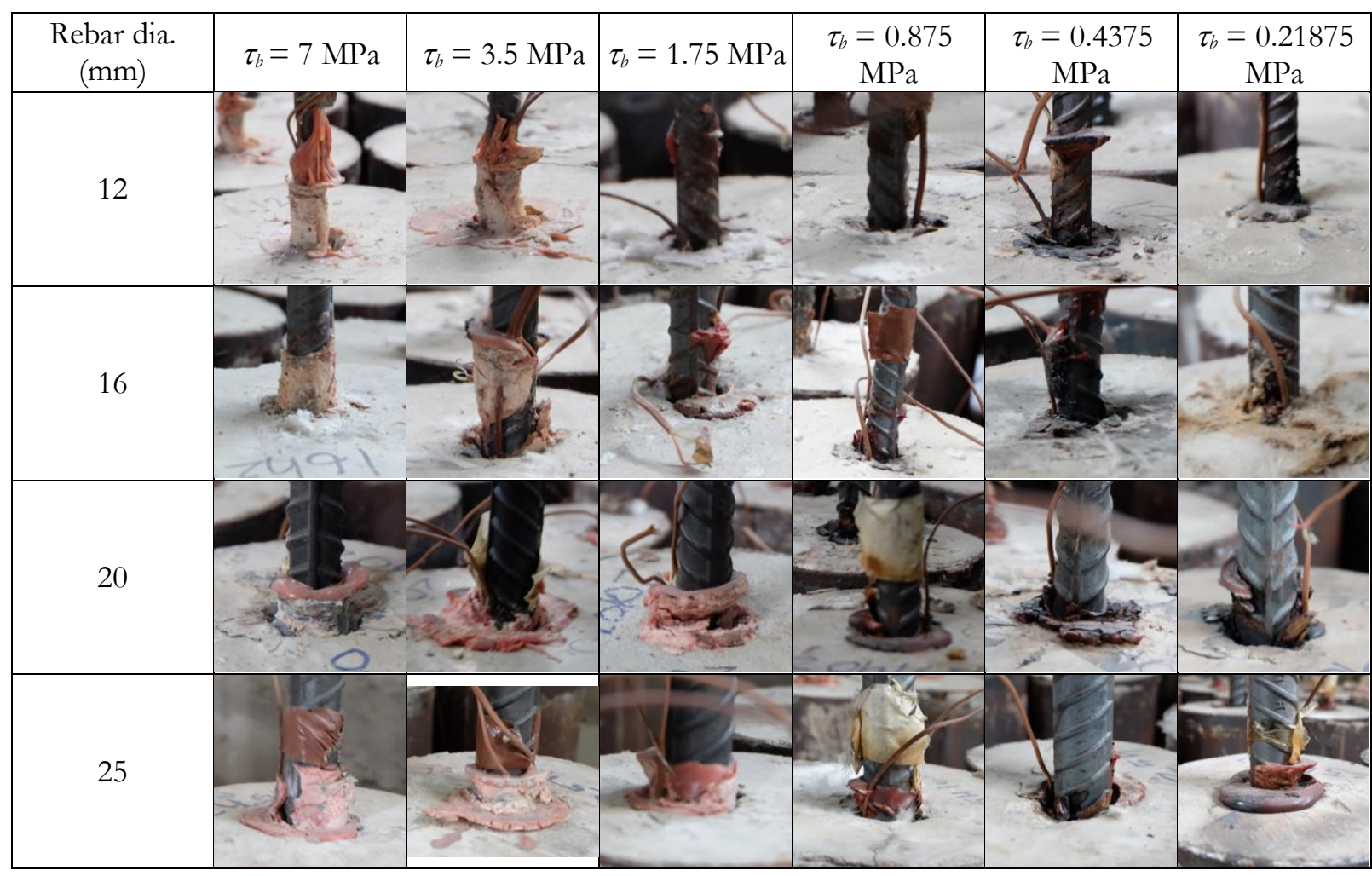

Table 8. Failure mode of the pull-out specimens using E2 epoxy resin.

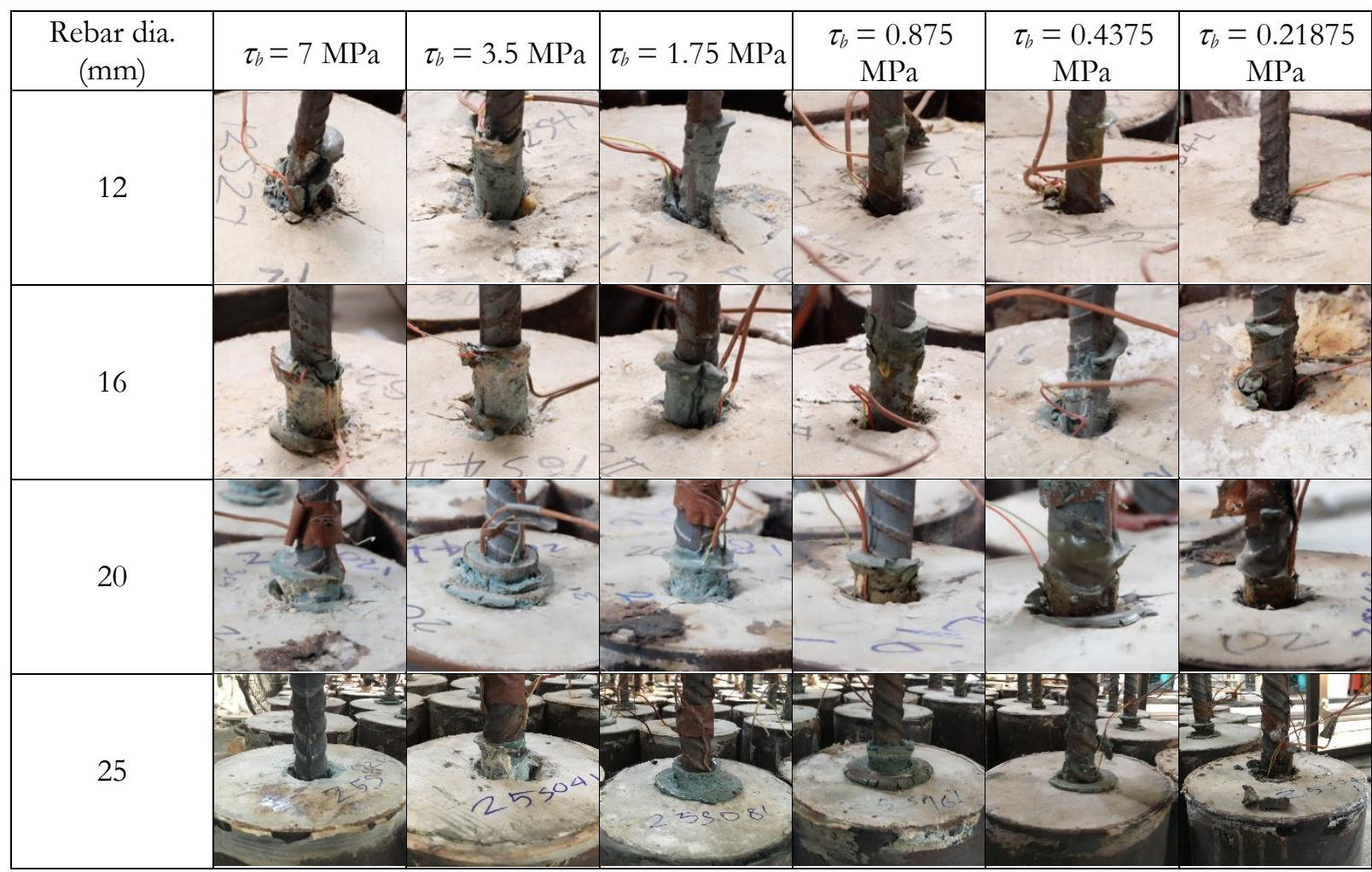




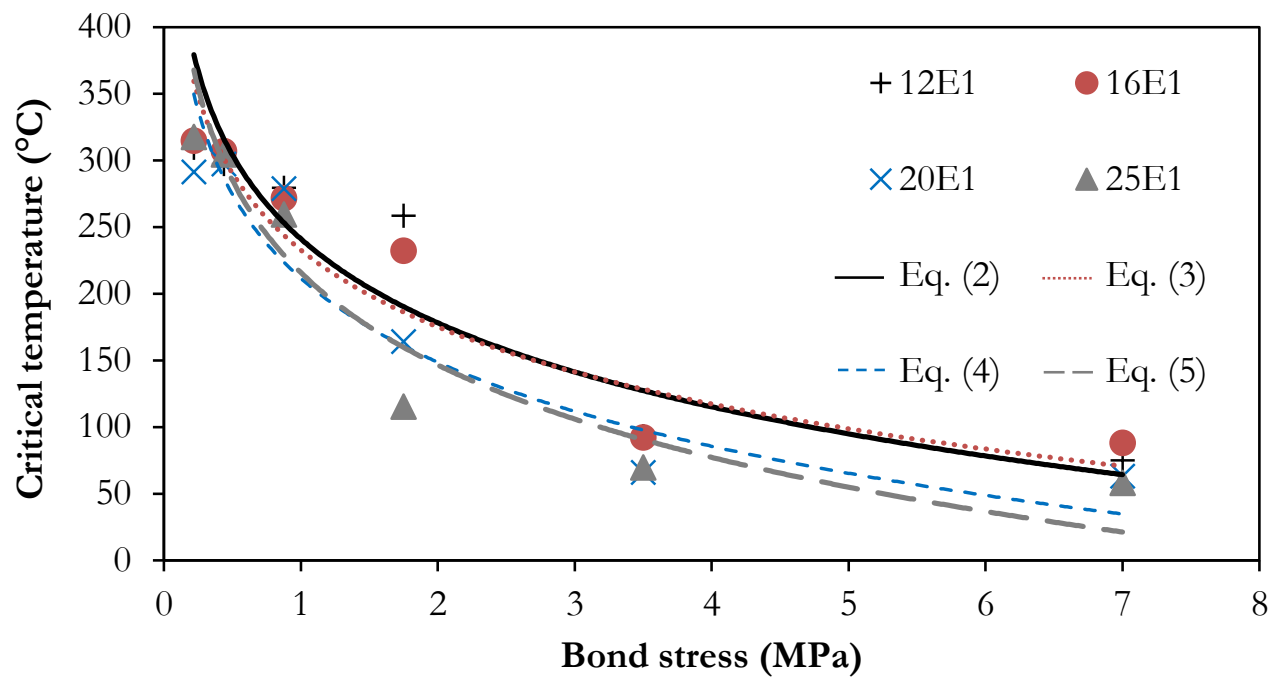

Fig. 3. Failure temperature-bond stress curve of E1 epoxy resin.

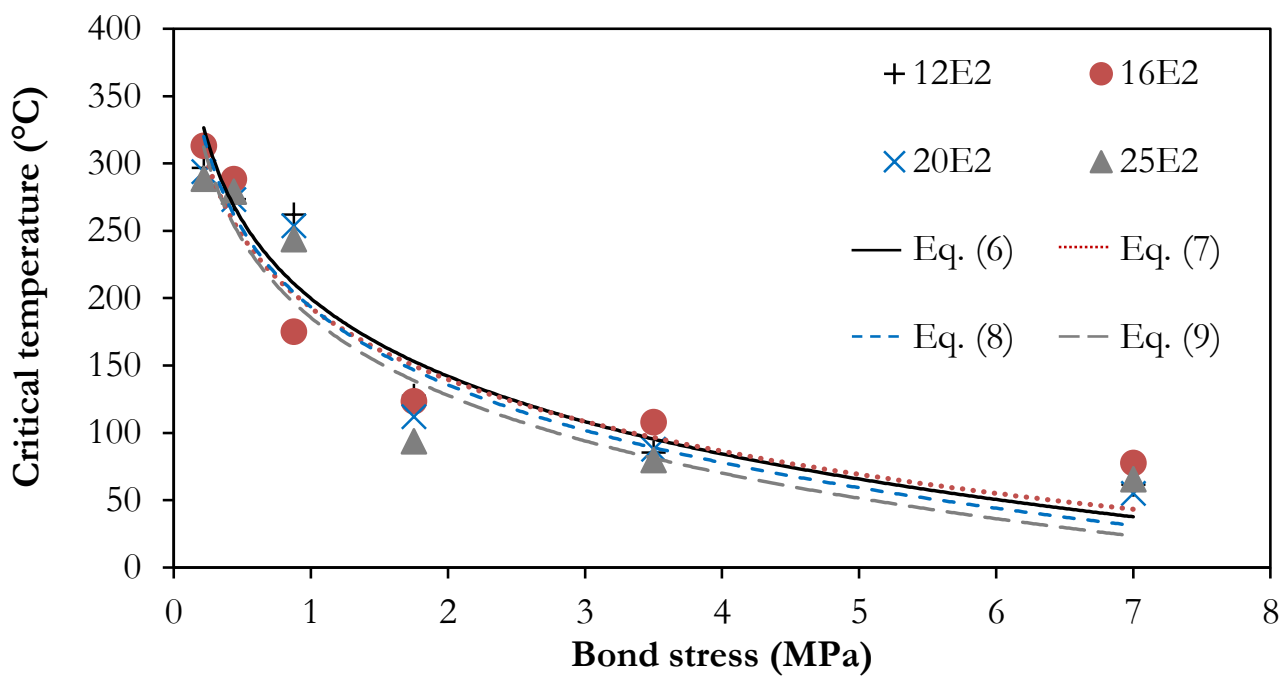

Fig. 4. Failure temperature-bond stress curve for E2 epoxy resin.

Table 9. Temperature-critical bond stress relationship.

\begin{tabular}{cccccccccc}
\hline $\begin{array}{c}\text { Rebar } \\
\text { dia. } \\
(\mathbf{m m})\end{array}$ & \multicolumn{1}{c}{ E1 } & Equations & $\begin{array}{c}\text { Eq. } \\
\text { No. }\end{array}$ & $\begin{array}{c}\mathbf{R}^{2} \\
(\%)\end{array}$ & $\begin{array}{c}\text { Standard } \\
\text { error }\end{array}$ & Equations & $\begin{array}{c}\text { Eq. } \\
\text { No. }\end{array}$ & $\begin{array}{c}\mathbf{R}^{2} \\
(\%)\end{array}$ & $\begin{array}{c}\text { Standard } \\
\text { error }\end{array}$ \\
\hline 12 & $\tau_{e}^{c r}\left(T_{e}\right)=14.2 e^{-0.011 T_{e}}$ & $(2)$ & 87.7 & 1.02 & $\tau_{e}^{c r}\left(T_{e}\right)=11.0 e^{-0.012 T_{e}}$ & $(6)$ & 88.7 & 0.97 \\
\hline 16 & $\tau_{e}^{c r}\left(T_{e}\right)=16.35 e^{-0.012 T_{e}}$ & $(3)$ & 82.1 & 1.23 & $\tau_{e}^{c r}\left(T_{e}\right)=12.28 e^{-0.013 T_{e}}$ & $(7)$ & 78.5 & 1.34 \\
\hline 20 & $\tau_{e}^{c r}\left(T_{e}\right)=10.26 e^{-0.011 T_{e}}$ & $(4)$ & 82.5 & 1.21 & $\tau_{e}^{c r}\left(T_{e}\right)=10.18 e^{-0.012 T_{e}}$ & $(8)$ & 88.1 & 1.00 \\
\hline 25 & $\tau_{e}^{c r}\left(T_{e}\right)=8.66 e^{-0.010 T_{e}}$ & $(5)$ & 81.1 & 1.26 & $\tau_{e}^{c r}\left(T_{e}\right)=9.27 e^{-0.012 T_{e}}$ & $(9)$ & 71.9 & 1.54 \\
\hline
\end{tabular}


Figure 4 compares failure temperatures for the E2 epoxy resin with different rebar sizes. A similar trend to the E1 epoxy resin is again observed. A significant drop of the failure temperature with increasing rebar diameter is observed at the bond stress of $1.75 \mathrm{MPa}$.

\subsection{A Mechanical Model for Adhesive Bond Stress at Elevated Temperature}

In order to examine the effect of rebar size on failure temperature, an analytical model for adhesive bonding between steel rebar and concrete interface at elevated temperature is presented herein based on the work of Bouazaoui and $\mathrm{Li}$ [4]. The proposed model accounts for the effect of varying temperature on the epoxy resin's modulus. In this model, it is assumed that at elevated temperatures the steel rebar, epoxy resin and concrete remain elastic and isotropic.

Let us consider a pull-out specimen which consists of a concrete cylinder, a steel rebar and an epoxy resin layer in between the steel/concrete interface under elevated temperature as shown in Fig. 5. The deformed steel rebar of nominal diameter $d_{b}$ is bonded by the epoxy resin layer of thickness $t_{e}$ in a concrete cylinder of diameter $d_{c}$. The embedded length of the steel rebar is $l_{b}$. The temperature of each material is denoted as $T_{c}$ for concrete, $T_{e}$ for epoxy resin and $T_{b}$ for steel rebar. Due to its low thermal diffusivity, the temperature of concrete generally decreases through its depth and the temperature is much lower at the concrete/epoxy resin interface compared with the exposed surface. Moreover, based on the experimental data in the previous section, the maximum failure temperature of epoxy resin measured at the epoxy resin/steel interface is $317.5^{\circ} \mathrm{C}$ (i.e., $T_{e} \leq 317.5^{\circ} \mathrm{C}$ ). At this temperature level, the mechanical properties of concrete and steel is assumed to vary insignificantly in comparison to the properties of the polymer adhesive, while above its glass transition temperature, the epoxy resin's modulus drops significantly.

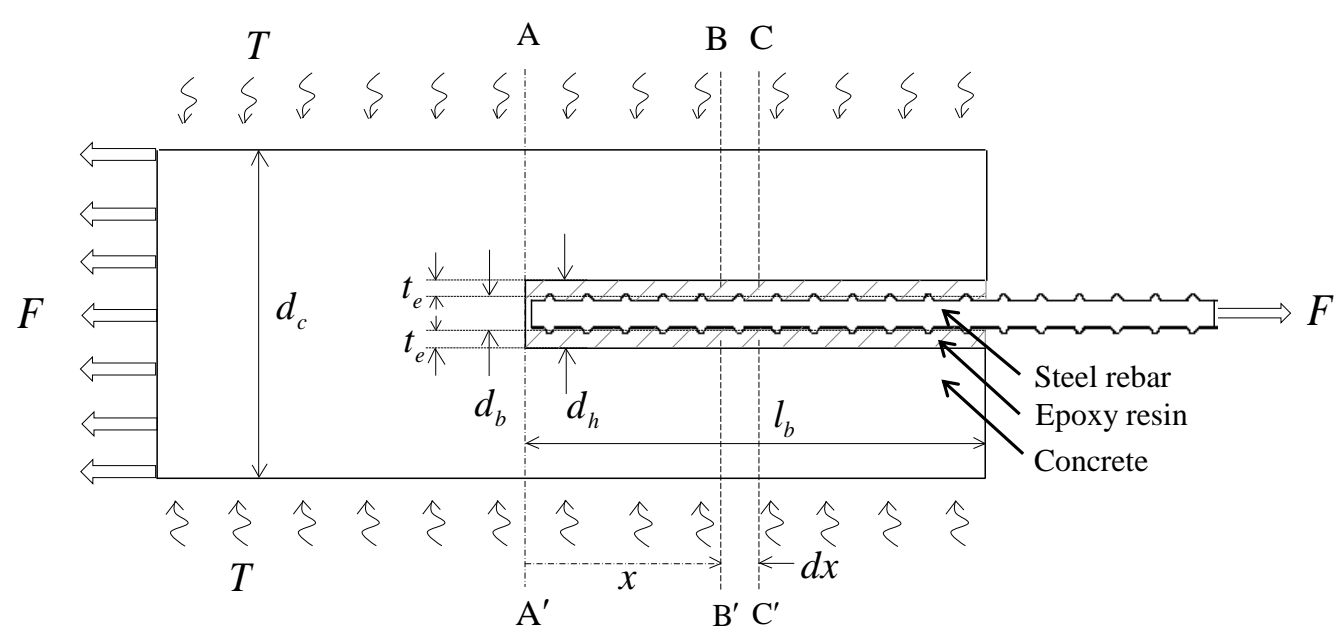

Fig. 5. Pull-out force transfer between a rebar and concrete. 


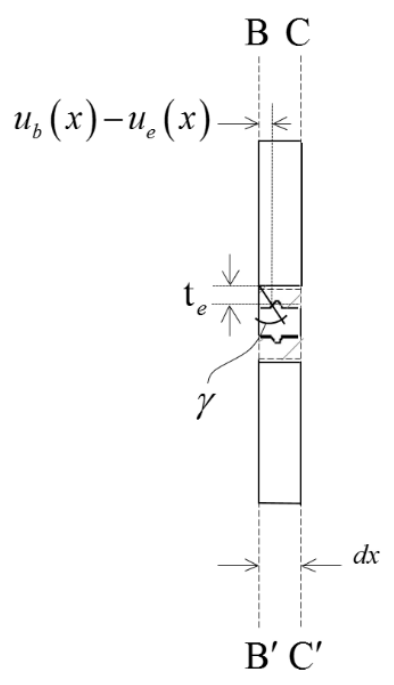

(a)

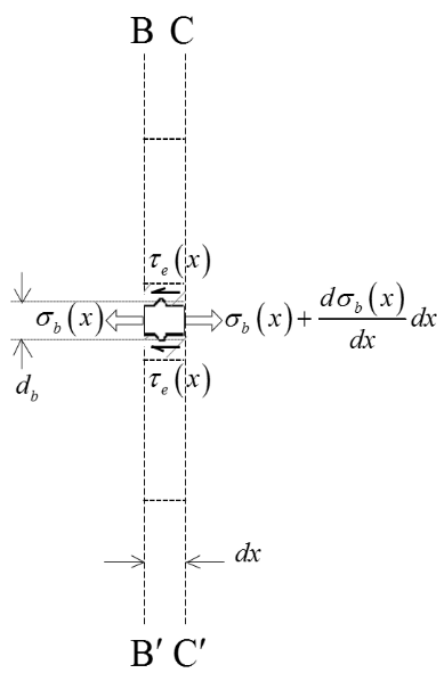

(b)
B

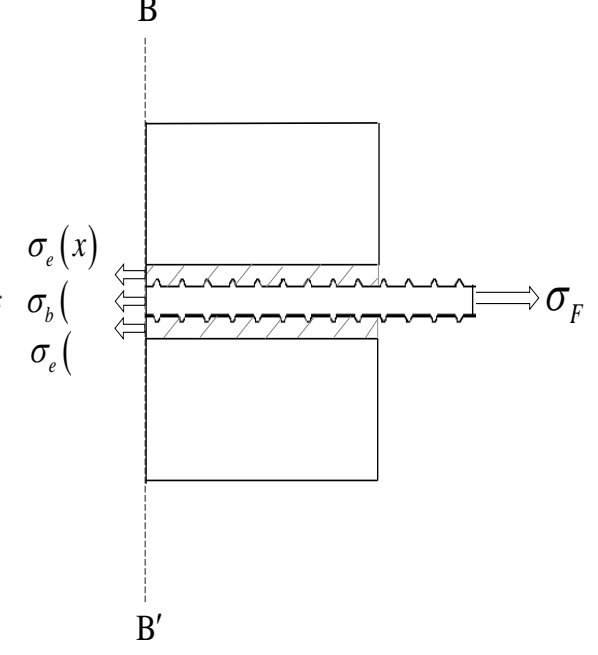

(c)

Fig. 6. Free body diagram of pull-out specimen. (a) Displacement and shear strain within the epoxy resin layer, (b) Interfacial shear stress and steel rebar axial stress, (c) Tensile stress in steel bar and epoxy resin

The applied pull-out force $F$ can be characterized as a constant external stress $\sigma_{F}$ in the longitudinal direction parallel to the steel rebar axis (Fig. 6(c)). Under this pull-out stress, the steel rebar and the epoxy resin deform elastically while the surrounding concrete matrix is assumed to remain in place. For an element $\mathrm{d} x$ of the test specimen (Fig. 6(a)), the shear strain within the epoxy resin layer is given by

$$
\gamma_{e}(x)=\frac{u_{b}(x)-u_{e}(x)}{t_{e}}
$$

Where $u_{b}(x)$ and $u_{e}(x)$ are the displacements of the steel rebar and the epoxy resin, respectively, $t_{e}$ is the epoxy resin thickness. Note that the shear plane based on the above equation is defined by the nominal diameter $d_{b}$ of the deformed steel rebar. Eq. (10) can be differentiated to obtain

$$
\frac{\mathrm{d} \gamma_{e}(x)}{\mathrm{d} x}=\frac{1}{t_{e}}\left(\frac{\mathrm{d} u_{b}(x)}{\mathrm{d} x}-\frac{\mathrm{d} u_{e}(x)}{\mathrm{d} x}\right)=\frac{1}{t_{e}}\left(\varepsilon_{b}(x)-\varepsilon_{e}(x)\right)
$$

where $\gamma_{e}(x)$ is the shear strain of the epoxy resin, $\varepsilon_{b}(x)$ and $\varepsilon_{e}(x)$ are the normal strains of the steel rebar and the epoxy resin, respectively.

Applying the relationships between stresses and strains, $\sigma=E \varepsilon$ and $\tau=G \gamma$, Eq. (11) can be rewritten as follows:

$$
\frac{\mathrm{d} \tau_{e}(x)}{\mathrm{d} x}=\frac{G_{e, T_{e}}}{t_{e}}\left(\frac{\sigma_{b}(x)}{E_{b}}-\frac{\sigma_{e}(x)}{E_{e, T_{e}}}\right)
$$

where $G_{e, T_{e}}$ and $E_{e, T_{e}}$ are the shear modulus and the elastic modulus of epoxy resin, which varies with its temperature $T_{e}, \sigma_{b}(x)$ and $\sigma_{e}(x)$ are the steel rebar stress and the epoxy resin stress, respectively. $E_{b}$ is the Young's modulus of steel which remains unaffected by the elevated temperature.

For the element $\mathrm{d} x$ (Fig. 6(b)), equilibrium of the interfacial shear stress $\tau_{e}(x)$ and the steel rebar axial stress $\sigma_{b}(x)$ can be expressed as 


$$
\tau_{e}(x) \cdot \pi d_{b} \mathrm{~d} x=\left(\frac{\mathrm{d} \sigma_{b}(x)}{\mathrm{d} x}\right) \frac{\pi d_{b}^{2}}{4} \mathrm{~d} x
$$

and

$$
\frac{\mathrm{d} \sigma_{b}(x)}{\mathrm{d} x}=\frac{4 \tau_{e}(x)}{d_{b}}
$$

Furthermore, equilibrium of the external stress $\sigma_{F}$, the steel rebar stress $\sigma_{b}(x)$ and the epoxy resin stress $\sigma_{e}(x)$ (see Fig. 6(c)) can be written as follows:

$$
A_{b} \sigma_{F}=A_{b} \sigma_{b}(x)+A_{e} \sigma_{e}(x)
$$

where $A_{b}$ and $A_{e}$ are the cross-sectional areas of the steel rebar and the epoxy resin, respectively. So, epoxy resin stress is obtained by

$$
\sigma_{e}(x)=\left(\sigma_{F}(x)-\sigma_{b}\right) \frac{A_{b}}{A_{e}}=\left(\sigma_{F}(x)-\sigma_{b}\right)\left(\frac{d_{b}^{2}}{d_{b}^{2}-d_{b}^{2}}\right)
$$

where $d_{b}=d_{b}+2 t_{e}$ is the total diameter of the concrete hole for steel rebar bonded by epoxy resin. Combining Eqs. (12), (14) and (16), the following differential equation is obtained:

$$
\frac{\mathrm{d}^{2} \sigma_{b}(x)}{\mathrm{d} x}=\frac{4 G_{e, T_{e}}}{d_{b} t_{e}}\left(\left(\frac{1}{E_{b}}+\frac{d_{b}^{2}}{E_{e, T_{e}}\left(d_{b}^{2}-d_{b}^{2}\right)}\right) \sigma_{b}(x)-\frac{d_{b}^{2}}{E_{e, T_{e}}\left(d_{b}^{2}-d_{b}^{2}\right)} \sigma_{F}\right)
$$

The above equation can be expressed as

$$
\sigma_{b}^{\prime \prime}(x)-\beta_{1}^{2} \sigma_{b}(x)+\beta_{2} \sigma_{F}=0
$$

where

$$
\beta_{1}^{2}=\frac{4 G_{e, T_{e}}}{d_{b} t_{e}}\left(\frac{1}{E_{b}}+\frac{d_{b}^{2}}{E_{e, T_{e}}\left(d_{b}^{2}-d_{b}^{2}\right)}\right) \text { and } \beta_{2}=\frac{4 G_{e, T_{e}} d_{b}}{E_{e, T_{e}} t_{e}\left(d_{b}^{2}-d_{b}^{2}\right)}
$$

The mathematical solution of Eq. (18) can be determined as follows:

$$
\sigma_{b}(x)=C_{1} \cosh \left(\beta_{1} x\right)+C_{2} \sinh \left(\beta_{1} x\right)+\sigma_{F} \frac{\beta_{2}}{\beta_{1}^{2}}
$$

where $C_{1}$ and $C_{2}$ are obtained by using the boundary conditions $\sigma_{b}(0)=0$ for $x=0$ and $\sigma_{b}\left(l_{b}\right)=\sigma_{\mathrm{F}}$ for $x=l_{b}$ :

$$
C_{1}=-\sigma_{F} \frac{\beta_{2}}{\beta_{1}^{2}} \quad \text { and } \quad C_{2}=\frac{\sigma_{F}}{\sinh \left(\beta_{1} l_{b}\right)}\left(1-\frac{\beta_{2}}{\beta_{1}^{2}}\left(1-\cosh \left(\beta_{1} l_{b}\right)\right)\right)
$$

From Eqs. (20) and (21), the normal stress distribution can be obtained as 


$$
\sigma_{b}(x)=\sigma_{F}\left[\frac{\beta_{2}}{\beta_{1}^{2}}\left(1-\cosh \left(\beta_{1} x\right)\right)+\frac{\sinh \left(\beta_{1} x\right)}{\sinh \left(\beta_{1} l_{b}\right)}\left(1-\frac{\beta_{2}}{\beta_{1}^{2}}\left(1-\cosh \left(\beta_{1} l_{b}\right)\right)\right)\right]
$$

By using Eqs. (14) and (22), the interfacial shear stress distribution can be estimated by

$$
\tau_{e}(x)=\frac{d_{b} \sigma_{F}}{4}\left[-\frac{\beta_{2}}{\beta_{1}} \sinh \left(\beta_{1} x\right)+\frac{\beta_{1} \cosh \left(\beta_{1} x\right)}{\sinh \left(\beta_{1} l_{b}\right)}\left(1-\frac{\beta_{2}}{\beta_{1}{ }^{2}}\left(1-\cosh \left(\beta_{1} l_{b}\right)\right)\right)\right]
$$

In order to determine $\tau_{e}$, the shear modulus $\left(G_{e, T_{e}}\right)$ and the elastic modulus $\left(E_{e, T_{e}}\right)$ of epoxy resin are required. Epoxy resin E1 is used herein to examine the efficacy of the proposed model. The epoxy resin was tested using Dynamic Mechanical Analysis (DMA) to obtain the elastic modulus of epoxy resin at $30^{\circ} \mathrm{C}$ $150^{\circ} \mathrm{C}$. However, since the maximum failure temperature in this study is $317.5^{\circ} \mathrm{C}$, the elastic modulus at higher temperatures (i.e., $T_{e}=150^{\circ} \mathrm{C}-320^{\circ} \mathrm{C}$ ) is therefore estimated using the reduction ratio for the elastic modulus of epoxy resins under elevated temperature derived from the literature [21]. Figure 7 presents the value of the elastic modulus with varying temperatures. It is seen from the figure that the elastic modulus dramatically drops between $60^{\circ} \mathrm{C}$ and $100^{\circ} \mathrm{C}$. After that, the elastic modulus decreases gradually with the increasing temperature.

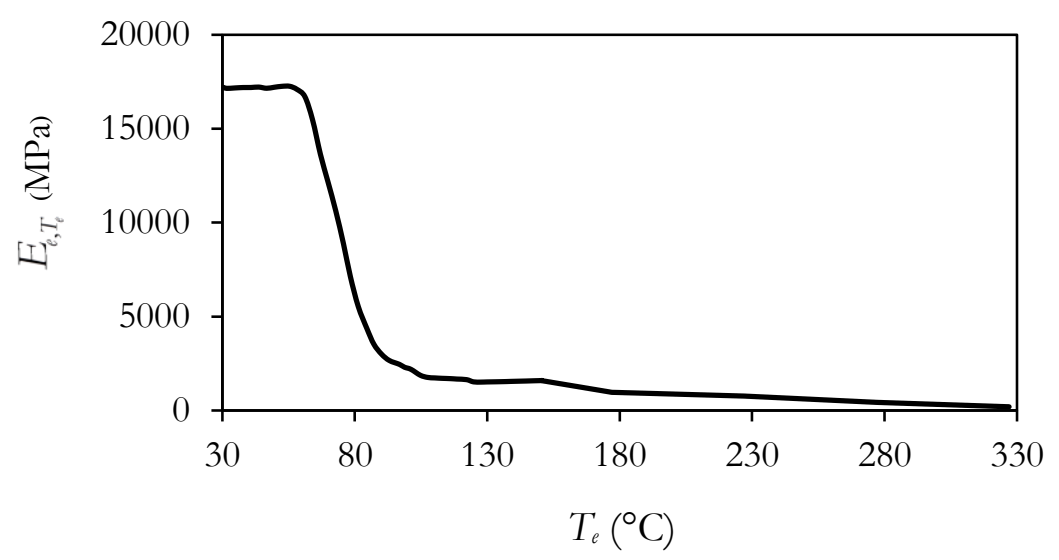

Fig. 7. Relationship between elastic modulus and temperature of epoxy resin.

The shear modulus can be determined by

$$
G_{e, T_{e}}=\frac{E_{e, T_{e}}}{2\left(1+v_{e, T_{e}}\right)}
$$

where $v_{e, T_{e}}$ is the Poisson's ratio of the epoxy resin at temperature $T_{e}$. Two methods are used to estimate the value of Poisson's ratio. The first method adopts the Poisson's ratio from Jeyranpour et al. [21] as shown in Fig. 8 while the second method regards the Poisson's ratio to be constant at 0.3 . Figure 9 presents the shear modulus of epoxy resin as calculated from Eq. (24) by using the two methods. Although the Poisson's ratios are slightly different in these methods, the values of the shear modulus are almost identical. The difference is only $3 \%$ when $T_{e}=30^{\circ} \mathrm{C}$ and this variation does not affect the modelling result under elevated temperatures. Therefore, in this paper, the Poisson's ratio of epoxy resin is taken as 0.3. 


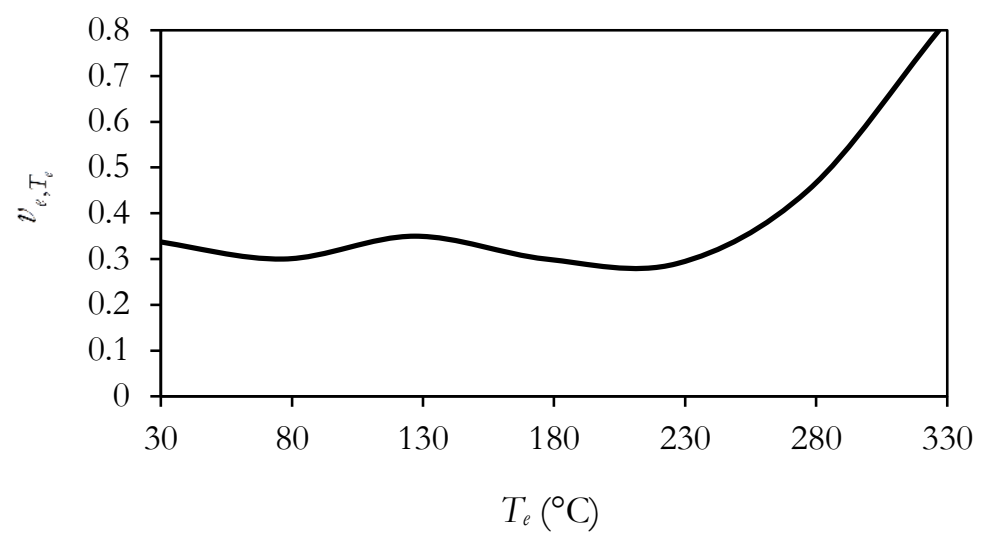

Fig. 8. Relationship between Poisson's ratio and temperature of epoxy resin [21].

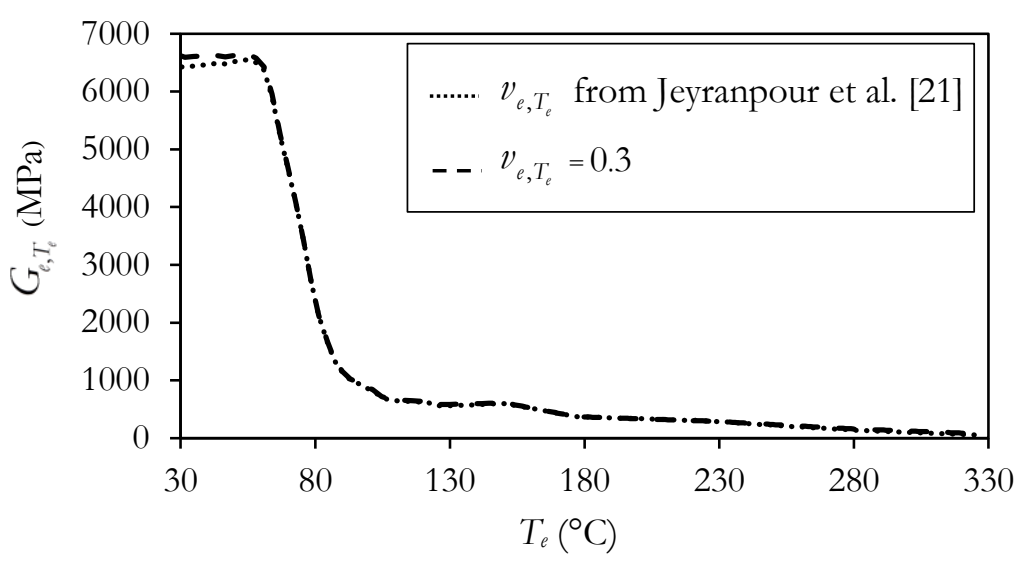

Fig. 9. Shear modulus of epoxy resin vs temperature.

The bond stresses of epoxy resin under elevated temperatures are examined by substituting $E_{b}, E_{e, T_{e}}$, $G_{e, T_{e}}, d_{b}, l_{b}, t_{e}$ and $\sigma_{\mathrm{F}}$ into Eq. (23). Figure 10 presents comparisons between the results obtained from the experiments, the empirical model and the mechanical model for DB12, DB16, DB20 and DB25, respectively. The coefficients of determination and standard errors for the mechanical model are also provided in Table 11.

According to the results, the mechanical model can illustrate the bond deterioration of the epoxy resin with respect to the increase in rebar diameter, which corresponds with the experimental results. The reduction of the critical temperature with increasing rebar diameter can be explained through Eq. (23). From this equation, it can be seen that at the same temperature the bond stress is higher for rebars with larger diameters, leading to failure of the bond at lower temperatures. Moreover, it is seen that the mechanical model provides better $\mathrm{R}^{2}$ and lower standard errors compared with the empirical model. However, the mechanical model requires input data on the elastic and shear moduli of the epoxy resin at elevated temperatures which are quite difficult to determine through testing. 


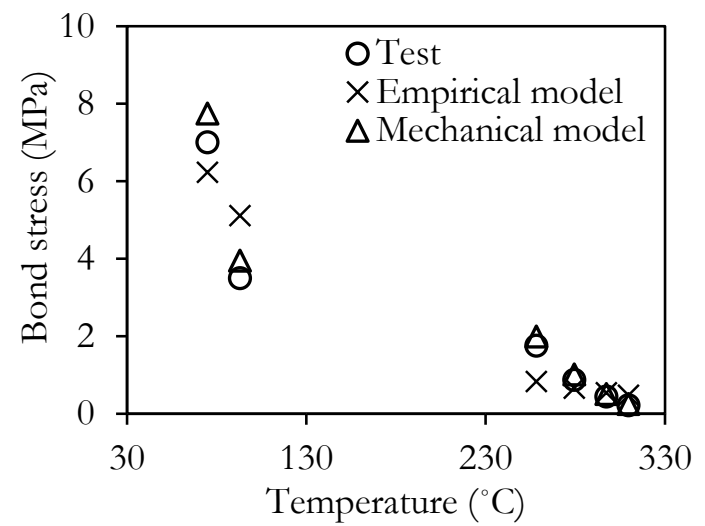

(a) DB12

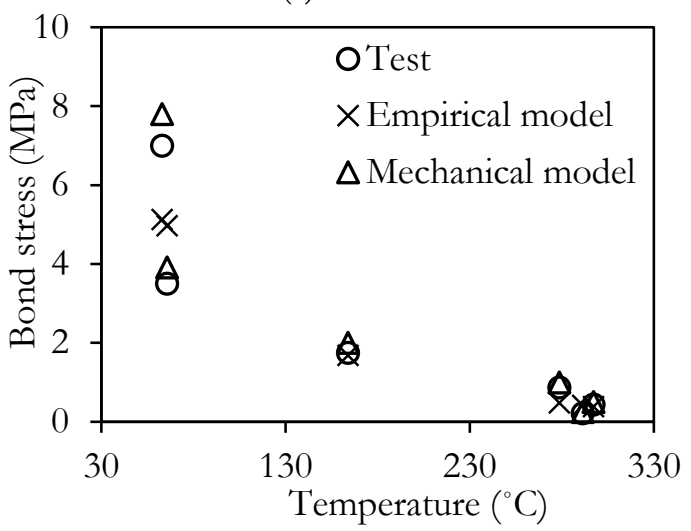

(c) DB20

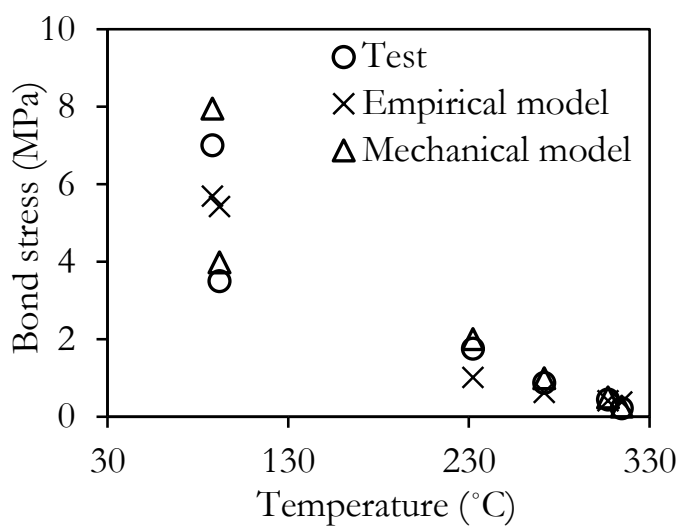

(b) DB16

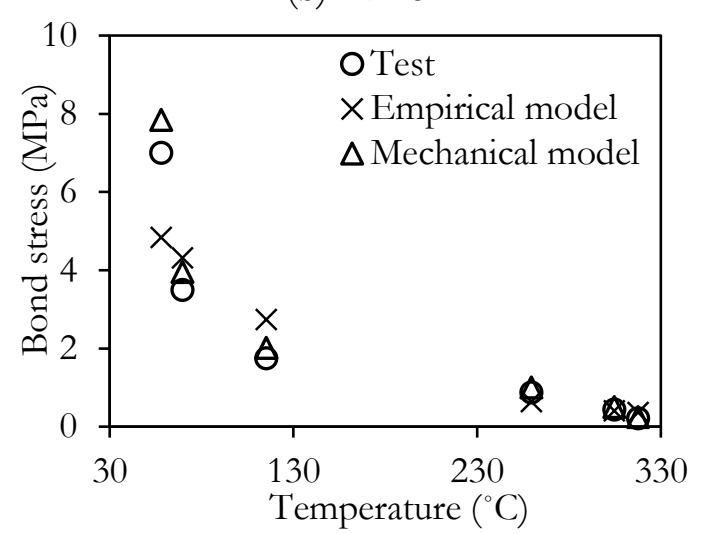

(d) DB25

Fig. 10. Comparison of the predicted bond strengths with the test results of epoxy E1. (a) DB12, (b) DB16, (c) DB20, (d) DB25.

Table 11. Accuracy of the mechanical model.

\begin{tabular}{ccc}
\hline Rebar diameter $(\mathbf{m m})$ & $\mathbf{R}^{\mathbf{2}} \mathbf{( \% )}$ & Standard error of estimates \\
\hline 12 & 98.0 & 0.46 \\
16 & 97.2 & 0.55 \\
20 & 97.9 & 0.48 \\
25 & 97.6 & 0.50 \\
\hline
\end{tabular}

\section{Conclusions}

The effect of rebar size on epoxy resin's bond has been investigated by performing pull-out tests at elevated temperatures. The bond deterioration of epoxy resins can be characterized by the relationship between bond stress and the critical temperature at failure. Test results show that the bond failure temperature decreases with the increase in the applied pull-out stress for a given rebar diameter. All of the specimens tested fail by shearing-off due to bond weakening. In addition, the bond failure tends to occur at lower temperatures for steel rebars with larger diameters. The effect of rebar size is more pronounced when the results are compared between the steel rebar with $12 \mathrm{~mm}$ and $25 \mathrm{~mm}$ diameters. A mechanical model has been proposed in the current study to examine the effect of rebar size on the bond deterioration of epoxy resins at elevated temperatures. The modelling results agree with the experimental results and confirm the effect of rebar size on bonding of steel reinforcement into concrete using epoxy resins under thermal loading.

\section{Acknowledgment}

This research was supported by the "Chulalongkorn Academic Advancement into Its $2^{\text {nd }}$ Century Project", Chulalongkorn University. 


\section{References}

[1] F. Hugenschmidt, "New experiences with epoxies for structural applications," Int J Adhes Adhes, vol. 2, no. 2, pp. 84-95, 1982.

[2] J. D. N. Shaw, "A review of resins used in construction," Int J Adhes Adhes, vol. 2, no. 2, pp. 77-83, 1982.

[3] T. O'Brien, "Resins in construction: feedback from structural applications," Int J Cem Compos Lightweight Concr, vol. 7, no, 4, pp. 233-239, 1985.

[4] L. Bouazaoui and A. Li, "Analysis of steel/concrete interfacial shear stress by means of pull out test," Int J Adhes Adhes, vol. 28, no. 3, pp. 101-108, 2008.

[5] A. Çolak, T. Çosgun, and A. E. Bakirci, "Effects of environmental factors on the adhesion and durability characteristics of epoxy-bonded concrete prisms," Constr Build Mater, vol. 23, no. 2, pp. 758-767, 2009.

[6] Ö. Çalışkan, S. Yılmaz, H. Kaplan, and N. Kıraç, "Strength of epoxy anchors embedded into low strength concrete," Constr Build Mater, vol. 38, pp. 723-730, 2013.

[7] S. Yilmaz, M. A. Özen, and Y. Yardim, "Tensile behavior of post-installed chemical anchors embedded to low strength concrete, " Constr Build Mater, vol. 47, pp. 861-866, 2013.

[8] A. Çolak, "Parametric study of factors affecting the pull-out strength of steel rods bonded into precast concrete panels," Int J Adhes Adhes, vol. 21, no. 6, pp. 487-493, 2001.

[9] M. McVay, R. A. Cook, and K. Krishnamurthy, "Pullout simulation of postinstalled chemically bonded anchors, "J Struct Eng, vol. 122, no. 9, pp. 1016-1024, 1996.

[10] A. Çolak, T. Çoşgun, and A. E. Bakırcı, "Effects of environmental factors on the adhesion and durability characteristics of epoxy-bonded concrete prisms," Constr Build Mater, vol. 23, no. 2, pp. 758-767, 2009.

[11] N. Pinoteau, P. Pimienta, T. Guillet, P. Rivillon, and S. Rémond, "Effect of heating rate on bond failure of rebars into concrete using polymer adhesives to simulate exposure to fire," Int J Adhes Adhes, vol. 31, no. 8, pp. 851-861, 2011.

[12] M. A. Lahouar, J.-F. Caron, N. Pinoteau, G. Forêt, and K. Benzarti, "Mechanical behavior of adhesive anchors under high temperature exposure: Experimental investigation," Int J Adhes Adhes, vol. 78, pp. 200-211, 2017.

[13] Q. Xie, C. J. Zhu, and H. X. Ju, "Numerical simulation of bond behavior for adhesive anchor in steelto-concrete connection exposed to fire," Applied Mechanics and Materials, vols. 351-352, pp. 860-864, 2013.

[14] A. F. Bingöl and R. Gül, "Residual bond strength between steel bars and concrete after elevated temperatures," Fire Safety J, vol. 44, no. 6, pp. 854-859, 2009.

[15] C. H. Chiang and C. L. Tsai, "Time-temperature analysis of bond strength of a rebar after fire exposure," Cem Concr Res, vol. 33, no. 10, pp. 1651-1654, 2003.

[16] R. D. Adams, J. Coppendale, V. Mallick, and H. Al-Hamdan, "The effect of temperature on the strength of adhesive joints," Int J Adhes Adhes, vol. 12, no. 3, pp. 185-190, 1992.

[17] X. Li, Y. Bao, N. Xue, and G. Chen, "Bond strength of steel bars embedded in high-performance fiberreinforced cementitious composite before and after exposure to elevated temperatures," Fire Safety J, vol. 92, pp. 98-106, 2017.

[18] ASTM C39 / C39M-17a, "Standard test method for compressive strength of cylindrical concrete specimens," ASTM International, West Conshohocken, PA, 2017.

[19] TIS 24-2548, "Steel bars for reinforced concrete: deformed bars," Thai Industrial Standards Institute (TISI), Thailand, 2005.

[20] R. A. Cook, J. Kunz, W. Fuchs, and R. C. Konz, "Behavior and design of single adhesive anchors under tensile load in uncracked concrete," ACI Struct J, vol. 95, no. 1, pp. 9-26, 1998.

[21] F. Jeyranpour, G. Alahyarizadeh, and B. Arab, "Comparative investigation of thermal and mechanical properties of cross-linked epoxy polymers with different curing agents by molecular dynamics simulation," J Mol Graph Model, vol. 62, pp. 157-164, 2015. 